\title{
Low back pain: a psychiatric investigation
}

\author{
S. N. WOLKIND \\ M.B., B.S., D.P.M. \\ Lecturer in Clinical Psychiatry, \\ The London Hospital Medical School, \\ London, E.1
}

\begin{abstract}
Summary
Middlesex Hospital Questionnaire scores of a group of male patients attending a physiotherapy department for treatment of low back pain distinguished between those patients with a good and those with a poor outoutcome.
\end{abstract}

Comparing the scores of these two groups with those of a normal male population suggests that there are two distinct populations of patients with low back pain.

A questionnaire may have a place in the selection of patients who are unlikely to respond to conventional treatment for low back pain and who need extensive social or psychiatric investigation.

\section{Introduction}

Low back pain is a common condition without an established pathology or aetiology. Treatment is controversial, and its outcome difficult to predict from the clinical presentation or from $\mathrm{X}$-ray findings.

Horal (1969), investigating back disorder in a large population in Gothenburg, selected a control group free from time off work due to spine disease; even in this group $66 \%$ had a past history of low back pain, at a mean age of 50 years. Rowe (1969) found that $50 \%$ of 140 men retiring from light industry at 65 years had been treated for low back pain. In a survey of British foundry-men over 35 years (Partridge et al., 1968), 63\% had a history of rheumatic disease, a rate similar to that in other countries. In this survey, back pain and lumbar disc disease accounted for $14 \%$ of all time lost from work. Horal similarly showed spinal disease responsible for $10-20 \%$ of days lost through illness. It has been suggested that in the United States low back disability is the top item in compensation payments in most industries (Rowe, 1969). Only upper respiratory infection exceeds low back pain or spinal disability as a cause for time lost from work.

It is widely stressed that accurate diagnosis of low back disorder presents unusual difficulties, and that the pathogenesis of back pain is not clearly established (Harrison, 1960; Hollander, 1960; Stevens, 1968). Specific anatomical abnormalities concerned have not been clearly identified. Structural abnor-

\author{
A. J. ForRest \\ M.B., B.S., D.P.M. \\ Senior Registrar in Psychiatry, \\ St George's Hospital, \\ London, S.W.17
}

malities seen on X-ray examination, although widely studied, are difficult to correlate with clinical symptoms (Harrison, 1960; Partridge et al., 1968; Horal, 1969; Rowe, 1969) and with the performance of the back under job-demands (Row, 1969).

Although psychological factors and psychiatric illness are frequently mentioned in relation to low back pain, there remains no established association. Patients claiming compensation for low back disorders do not seem to differ in their psychological make-up, or success in life and work, from those claiming for other causes (Collette \& Ludwig, 1968). In the survey of iron-foundry workers (Partridge et al., 1968) Maudsley Personality Inventory scores bore no relation to the presence or absence of rheumatic disease, to the presence of concomitant non-rheumatic symptoms, or to time spent off work.

The present paper relates outcome of treatment to initial psychological assessment using the Middlesex Hospital Questionnaire, a self-rating scale of psychoneurotic symptoms and behaviour. The test provides a measure of general emotionality, or 'neuroticism', together with a profile of six sub-tests scores, measuring respectively free-floating anxiety (FFA), phobic anxiety (PHO), obsessionality (OBS), somatic concomitants of anxiety (SOM), depression (DEP) and hysterical personality (HYS).

\section{Subjects}

The subjects were fifty consecutive male patients referred to a general hospital department of physiotherapy for treatment of low back pain, and able to complete the Middlesex Hospital Questionnaire. Fifty-two men were approached: one did not complete all questions and one refused to co-operate. Patients were accepted for the study if their diagnosis was low back pain, or lumbar-sacral strain. Patients were excluded when an initial diagnosis of intervertebral disc lesion was supported by signs of local nerve pressure or localized $\mathrm{X}$-ray changes.

\section{Procedure}

Each patient on his first day at the physiotherapy department was asked to complete the Middlesex 
Hospital Questionnaire; it was explained that this was a survey to discover the prevalence of symptoms in different groups of patients. The Questionnaire was sealed, and neither the doctor approaching the patient nor the physiotherapist was allowed to see the completed questionnaire, nor informed of the score.

After six treatment sessions, usually occurring over a 3-week period, patients were asked to complete a self-rating questionnaire to describe their present clinical state. Those patients who terminated treatment prior to six sessions were contacted by post 3 weeks after the beginning of their treatment. Completed questionnaires were obtained from forty-six patients; in the remaining four patients an assessment of the patient's state was made from the notes of the follow-up appointment, in the department of physical medicine. Patients symptom-free or having only minor symptoms were classified in a 'Good Outcome' group: patients still with handicapping symptoms were classified as 'Poor Outcome'.

\section{Results}

On the self-rating questionnaire, twenty-seven patients described themselves as having no, or minimal symptoms, and twenty-three as having handicapping symptoms or as being worse. The mean age of the Good Outcome group was 35.1 years and that of the Poor Outcome group 43.6 years. This difference is significant at the 0.05 level. Table 1 shows the scores of the two groups on the Middlesex Hospital Questionnaire. In all sub-scores the Poor Outcome group had higher mean scores. On the somatic scale this reaches the 0.001 level of significance; obsessional and depressive scores were significant to the 0.01 level. There were no significant differences between the groups on the anxiety, phobic and hysteria scores.

A cut-off point was taken on the somatic scale which divided the patients into two groups of approximately equal size to the Outcome groups. This score (7 points) had marked predictive value. Of nineteen patients with a score of 7 or over, fifteen had a poor result: of thirty-one with the score below 7, only eight had a poor result. This difference in proportions $(79 \cdot 5-25 \cdot 6 \%)$ is significant at the 0.001 level.

The scores of each of the two groups were compared with the data on 1288 men employed by the Atomic Energy Authority (Crown, Duncan \& Howell, 1970); Table 2 shows the scores.

TABLe 1.

\begin{tabular}{|c|c|c|c|c|c|c|}
\hline & FFA & PHO & OBS & SOM & DEP & HYS \\
\hline \multicolumn{7}{|l|}{ Good responders $(n=27)$} \\
\hline Mean & $4 \cdot 85$ & $2 \cdot 81$ & 6.07 & $3 \cdot 89$ & $3 \cdot 52$ & $4 \cdot 78$ \\
\hline \multicolumn{7}{|l|}{ Poor responders $(n=23)$} \\
\hline Mean & $5 \cdot 70$ & $4 \cdot 04$ & $8 \cdot 35$ & $8 \cdot 35$ & $5 \cdot 17$ & $5 \cdot 22$ \\
\hline Pooled SD & $3 \cdot 68$ & $2 \cdot 38$ & 3.73 & $3 \cdot 16$ & $2 \cdot 87$ & 3.63 \\
\hline Difference between means & 0.85 & $1 \cdot 23$ & $2 \cdot 28^{*}$ & $4.46 \dagger$ & $1 \cdot 66^{*}$ & 0.44 \\
\hline SE of difference & $1 \cdot 041$ & 0.672 & 1.055 & $0.8943^{*}$ & $0.812^{*}$ & 1.004 \\
\hline
\end{tabular}

Differences tested with $t$ test with 48 degrees of freedom using pooled SD in formula:

$$
\text { SE of difference }=\sqrt{s^{2} \frac{1}{n_{1}}+\frac{1}{n_{2}}}
$$

* Significant at 0.05 level.

$\dagger$ Significant at 0.001 level.

TABLe 2.

\begin{tabular}{lcccccc}
\hline & FFA & PHO & OBS & SOM & DEP & HYS \\
\hline AEA males $(n=1208)$ & $3 \cdot 1$ & 2.3 & 6.7 & 3.8 & 2.5 & 2.7 \\
Good responders $(n=27)$ & 4.9 & 2.8 & 6.1 & 3.9 & 3.5 & 4.8 \\
Poor responders $(n=23)$ & 5.7 & 4.0 & 8.3 & 8.3 & 5.1 & 5.2 \\
Difference between means & & & & & & \\
GR + AEA & $1.8 *$ & 0.5 & 0.6 & 0.1 & 1.0 & $2 \cdot 1 \dagger$ \\
SE of difference & 0.71 & 0.46 & 0.72 & 0.61 & 0.55 & 0.70 \\
Difference between means & & & & & \\
PR + AEA & $2.6 \ddagger$ & $1.7 \ddagger$ & $1.6 \dagger$ & $4.5 \ddagger$ & $2.6 \ddagger$ & $2.5 \ddagger$ \\
SE of difference & 0.77 & 0.50 & 0.78 & 0.66 & 0.60 & 0.76 \\
\hline
\end{tabular}

AEA, Atomic Energy Authority; GR, Good Outcome group; PR, Poor Outcome group. 
The Good Outcome group differed significantly from the normals only on the scales of anxiety (at the 0.05 level) and hysteria (at the 0.01 level). In contrast, the Poor Outcome group had higher scores than the normals in all sub-scales, significant at the 0.01 level for obsessionality and at the 0.001 level for all other sub-scores.

\section{Discussion}

After 3 weeks, $54 \%$ of patients had done well. It is not possible to say from this paper to what extent this is a result of treatment, but the figures compare with White's series of patients attending a rehabilitation centre for persistent back pain (White, 1966). He found $49 \%$ showed satisfactory improvement.

Comparing the two groups of patients, clear differences are seen in their scores on the somatic, obsessional and depressive scales. Crown et al. (1970) found that obsessional and depressive scores were significantly higher in men over 47 compared with men under that age, but somatic scores were not affected by age. Crisp \& Priest (1971), in a general practice sample of married men, found that the somatic score was higher in men over 60 , but there was no consistent rise with age in under-sixties. Though the depressive and obsessional score differences may be related to the age difference between the groups, the somatic scale difference appears to reflect other differences between the groups. Evidence that age is not an important factor is obtained from White's series, showing no relationship between age and ultimate outcome. Of more interest is the comparison of each of the patient groups with the Atomic Energy Authority normal population. The Good Outcome group has scores similar to the normal population on four scales. The two scales on which they attained significantly higher scores may well be non-specific effects. The hysteria scale needs to be treated with some reserve: the relationship of the hysterical personality which the scale tends to measure to the concept of conversion hysteria as a psychoneurotic disorder remains a problem. Crown et al. (1970) have shown that high scores on this scale are related to youth and sex. It is possible that the anxiety scale difference, significant at the 0.05 level, is related to being ill and attending a hospital.

However, it should be noted, on the basis of the constancy of the incidence of rheumatic complaints between various industries, that $50 \%$ of the employees in the Atomic Energy Commission would have experienced treatment for low back disorder by retirement.

The Poor Outcome group, however, differs markedly from the normal population on every scale and it would appear that these patients, unlike the Good Outcome group, cannot be looked upon as a sample of the normal population but rather as an abnormal population, with low back pain being a presenting symptom of a more diffuse disorder involving many aspects of personality and functioning.

The possibility, however, that their scores merely reflect a clinically similar, but more severe low back pain than that of the Good Outcome group must be considered. One question on the somatic scale relates to paraesthesiae, but as patients with neurological symptoms were excluded from the study this is unlikely to have affected the results. A more severely ill group might respond to the question concerning fear of incurable illness within the phobic scale, but the two groups did not differ in their mean scores for this scale. It hence seems most unlikely that it is methodological bias in the questionnaire which produces the differences. Duration of illness might be related to both poor prognosis and high scores, but*, however, with a condition as difficult to evaluate as is low back pain only a prospective study could show this.

For patients who fail to respond to treatment in a physiotherapy department further management is not clear. Partridge found the Maudsley Personality Inventory of no help in differentiating between prognostic groups. It is felt that the results from this paper, using a questionnaire based on psychiatrice symptoms, not only suggest that there are two? populations of patients with back pain and possibly two syndromes, but also offer an aid in the investigation of patients who have failed to respond to an initial course of treatment. High Middlesex Hospital Questionnaire scores, especially on the somatic scales, might be taken as an indication for more extensive social or psychiatric evaluation of these patients.

* It is unlikely, too, that scores on sub-tests as specific as obsessionality and depression would be affected by longstanding physical illness.

\section{Acknowledgments}

We wish to thank Professor D. A. Pond for his encouragement and interest in the study, and the physicians of the Physical Medicine Department of the London Hospital for allowing us to investigate patients under their care. We wish, too, to thank the physiotherapists and patients for giving so willingly of their time.

\section{References}

Collette, J. \& Ludwig, E.G. (1968) Low back disorders; an examination of a stereotype. Industrial Medicine and Surgery, 37, 685.

CrisP, A.H. \& Priest, R.G. (1971) Psychoneurotic profiles in middle-age. British Journal of Psychiatry, 119, 385. 
Crown, S. \& CrisP, A.H. (1966) A short clinical diagnostic self-rating scale for psychoneurotic patients: The Middlesex Hospital Questionnaire. British Journal of Psychiatry, $112,917$.

Crown, S., Duncan, K.P. \& Howell, R.W. (1970) Further evaluation of the Middlesex Hospital Questionnaire. British Journal of Psychiatry, 116, 33.

Harrison, T.R., (Ed.) (1960) Principles of Internal Medicine. McGraw-Hill Book Co., London.

Hollander (Ed.) (1960) Arthritis and Allied Diseases, Chap. 71. Lea and Febiger, U.S.A.

Horal, J. (1969) The clinical appearance of low back disorders in the city of Gottenburg, Sweden. Acta orthopaedica Scandinavica (Suppl. 108), 1, 118.
Partridge, R.E.H., Anderson, J.A.D., McCarthy, M.A. \& DuthiE, J.J.R. (1968) Rheumatic complaints among workers in iron foundries. Annals of the Rheumatic Diseases, 27, 441.

Rowe, M.L. (1969) Low back pain in industry: a position paper. Journal of Occupational Medicine, 11, 161.

Stevens, J. (1968) Low back pain. Medical Clinics of North America, 52, 55.

WhITE, A.W.M. (1966) Low back pain in men receiving workman compensation. Canadian Medical Association Journal, 95, 50. 